\title{
Rhabdoid Meningioma
}

National Cancer Institute

\section{Source}

National Cancer Institute. Rhabdoid Meningioma. NCI Thesaurus. Code C6909.

A WHO grade III meningioma characterized by the predominant presence of rhabdoid cells forming sheets. 